\title{
Reversal of Normal Pressure Hydrocephalus Symptoms by Subdural Collections
}

\author{
C. M. Fisher
}

\begin{abstract}
Background: The pathogenesis of symptoms in normal pressure hydrocephalus (NPH) is unclear. One theory is that in the presence of enlarged lateral ventricles, the ventricular fluid exerts increased force on the ventricular walls, the cerebrospinal fluid pressure remaining normal. This is in accordance with Pascal's principle of F = PxA. It has not been possible to obtain direct evidence for this view. Method: The opportunity to gain insight into the matter arose when it was observed that two patients with symptomatic NPH were relieved of their symptoms when they developed bilateral subdural collections, one after head trauma, the other after ventriculo-peritoneal shunting for NPH. Result: In each case, concomitant with the subdural collections and the reversal of symptoms, the ventricular system became smaller. In the first patient, symptoms returned when the subdural collections were resorbed. In the second patient, symptoms returned when the subdural collections became excessive. Conclusion: Although documentation was less thorough than desired, it was concluded that relief of symptoms was related to the decrease in the ventricular size rather than lowering of the intraventricular pressure, thus providing evidence for operation of the principle $\mathrm{F}=\mathrm{PxA}$ as the mechanism of symptoms in NPH.
\end{abstract}

RÉSUMÉ: Régression des symptômes d'hydrocéphalie normotensive suite à la formation d'une collection sous-durale. Introduction: La pathogenèse des symptômes de l'hydrocéphalie normotensive (HNT) est mal connue. Selon une théorie, si les ventricules latéraux sont agrandis, le liquide ventriculaire exerce une force accrue sur les parois ventriculaires et la pression demeure normale, selon le principe de Pascal F = P x S. Il n'a pas été possible d'obtenir de preuve directe en faveur de cette théorie. Méthode: L'occasion d'en connaître davantage sur ce sujet s'est présentée quand on a constaté que deux patients présentant une HNT symptomatique ont été soulagés de leurs symptômes quand ils ont développé une collection sous-durale bilatérale, l'un après un traumatisme crânien et l'autre après une dérivation ventriculo-péritonéale pour son HNT. Résultats: Dans chaque cas, avec la formation de collections sous-durales et la disparition des symptômes, le système ventriculaire a rétréci. Chez le premier patient, les symptômes sont réapparus quand les collections sous-durales se sont résorbées. Chez l'autre, les symptômes sont réapparus quand les collections sous-durales sont devenues importantes. Conclusion: Bien que la documentation n'ait pas été aussi exhaustive que souhaitée, le soulagement des symptômes a été attribué à la diminution de la taille ventriculaire plutôt qu'à une diminution de la pression intraventriculaire, ce qui est en faveur du principe $\mathrm{F}=\mathrm{P} \times \mathrm{S}$ comme mécanisme responsable des symptômes de l'HNT.

Can. J. Neurol. Sci. 2002; 29: 171-174

The early manifestations of idiopathic symptomatic normal pressure hydrocephalus (NPH) are gait imbalance, urinary urgency and slowness and decrease of action and thought. As the process advances these disturbances become progressively worse. Ventriculo-peritoneal shunting, when successful, reverses the symptoms, restoring the patient to normal.

That functional impairment should occur with normal CSF (ventricular) pressure is explained by the associated enlargement of the ventricular system, the force on the ventricular wall increasing as the ventricle enlarges. This is in accordance with Pascal's hydraulic principle for fluids in which $\mathrm{PxA}=\mathrm{F}$ where $\mathrm{P}$ is the CSF pressure, $\mathrm{A}$ is the area of the ventricular surface and $\mathrm{F}$ is the force per unit area of the ventricular surface. When A increases, $\mathrm{F}$ also increases, while the pressure remains the same. The application of Pascal's Law explains the dynamic aspects of hydrocephalus but proving that it is the correct explanation has been elusive. ${ }^{1}$

This paper describes two patients with NPH in which bilateral subdural collections resulted in reversal of the clinical deficits

From the Neurology Service, Massachusetts General Hospital, Boston, MA, USA. ReCEIVEd August31, 2001. ACCEPTED IN Final FORM JANUARY 9, 2002. Reprint requests to: C. M. Fisher, Neurology Service, Massachusetts General Hospital, Fruit Street, VBK 910, Boston, MA, 02114, USA 


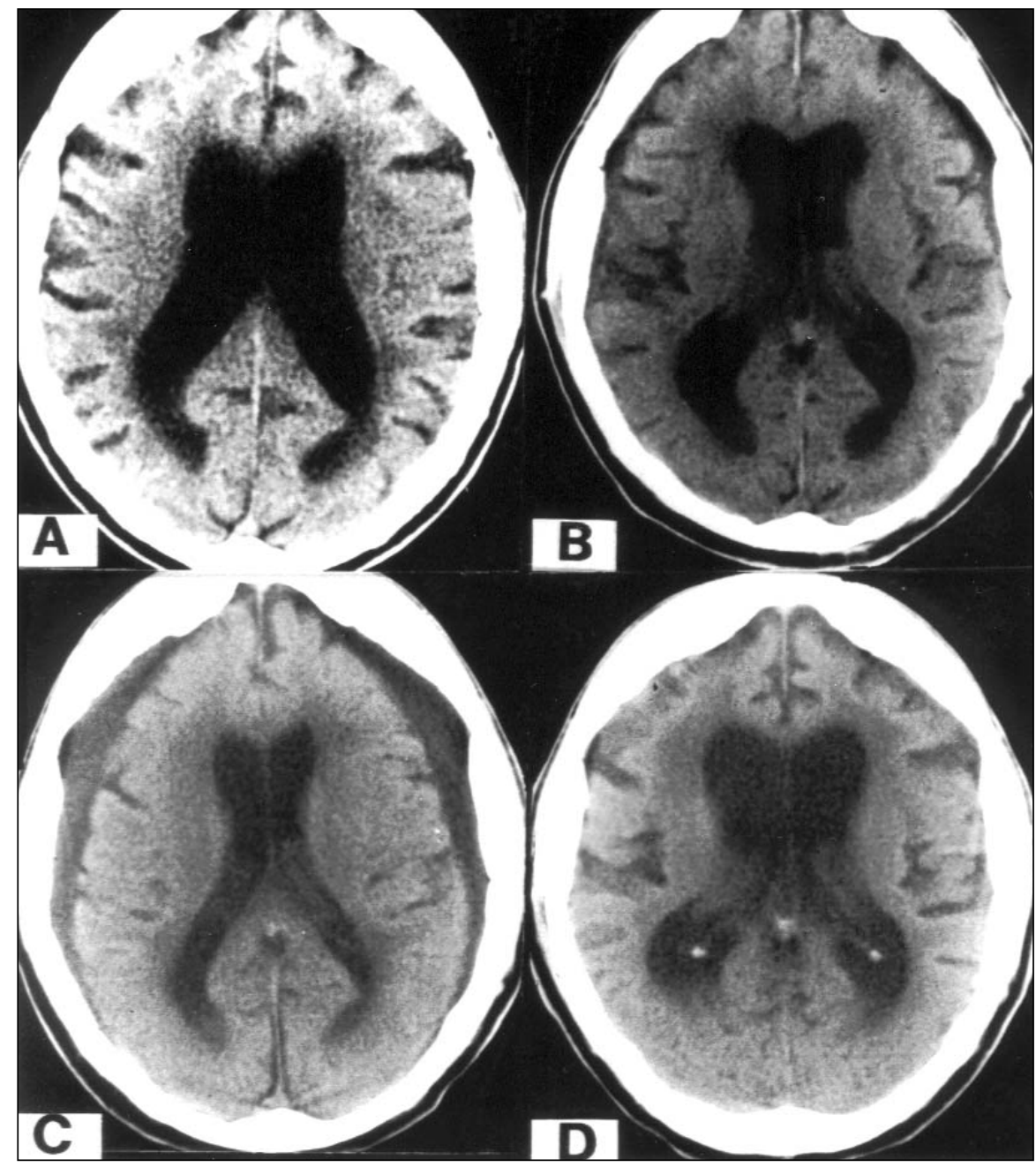

Figure 1: Patient 1. Cranial CT scans. A: Pretrauma hydrocephalus; B: At time of head injury, small subdurals; $C$ : Eight days after trauma showing larger subdurals and smaller ventricles; D: Three months after trauma with subdurals resorbed and ventricles re-enlarged.

accompanied by a decrease in the size of the ventricles, providing evidence that ventricular size per se contributes to the clinical symptoms. In patient 1 , the subdurals followed head injury in a patient under long-term observation for NPH. In patient 2, ventriculo-atrial shunting was performed in a patient with advanced NPH.

\section{Patient 1}

A 55-year-old man stumbled and fell on concrete steps at a sporting event, striking his occiput. He was stunned but not unconscious and was immediately transported to an Emergency Department where he was described as stuporous with an expressive-receptive aphasia. A cranial CT scan showed bilateral hydrocephalus with small subdural collections. (Figure 1B).

The patient had been under medical care for approximately 10 years because of imbalance on walking, attributed to hydrocephalus shown in CT scans. This past history is of particular relevance and will be presented at this point. There had been a slight but definite progression of symptoms over the years and for two years he had used a cane. There was urinary urgency and occasional bowel incontinence. He also was obliged to accept early retirement from his executive position because of staggering gait, (age 54). He had fallen several times. At the age of 20 he had acute meningitis from which he recovered satisfactorily. It was suspected that the hydrocephalus was a sequela of that illness.

Over the years he was examined regularly. The only positive findings were slowness of gait (3/4 normal speed), a widened base, staggering on pivoting and a positive romberg test. The patient was large framed and weighed $230 \mathrm{lbs}$. An unusual finding was the presence of occasional action myoclonus of moderate amplitude involving the left arm and leg. Formal neuropsychological testing showed evidence of significant decline from his estimated normal capability but this was not evident in his work. He had a master's degree in business administration.

Cranial CT scans every year or two showed hydrocephalus with a ventricular size within the symptomatic range for NPH (Figure 1A). There was little or no change in the ventricular size over the years. A test 
withdrawal of lumbar CSF produced no clinical improvement. It was concluded that his disability was insufficient to warrant ventriculoperitoneal shunting.

It was on this background that the patient's cranial injury occurred. In the three days after admission to the hospital his speech difficulty gradually improved. A lumbar puncture on hospital day 2 showed an initial pressure of $130 \mathrm{mmcsf}$. The presence of red blood cells was attributed to a traumatic tap. A repeat CT scan on hospital day 8 showed bilateral moderate-sized subdural hygromas (Figure 1C), most likely representing evolving subdural hematomas. The lateral ventricles were smaller, the ventricular span at the level of the bodies being reduced to $13 \mathrm{~mm}$ from $19 \mathrm{~mm}$. At this time the family members (wife and two adult children) noted a "remarkable" improvement in the patient's mobility. His walking was "unbelievable". He arose from a chair with ease and in the corridor walked ahead of the family whereas usually he had difficulty keeping up. He did not need a cane or walker. He walked better than he had in years. He went up and down stairs several times. Other descriptions by the family were "dramatic improvement" and "his walking was so good". The notes of the physiotherapist corroborated the family's observations. It was decided to treat the subdurals nonsurgically and the patient was discharged to his home the following day, before the family had an opportunity to bring the improved mobility to the attention of the staff. We are dependent, therefore, on the observations of the family. However, their long-term experience with the patient's state may have made them especially reliable witnesses.

The improvement was temporary and in three weeks his walking was again unstable. On a repeat $\mathrm{CT}$ scan the subdural collections were smaller and the ventricular size had increased. In three months the subdurals were almost completely resorbed and the ventricles were larger than before the head injury (Figure 1D). Gait and stance had gradually become more impaired making a wheelchair necessary. Intellect was probably more impaired. Urinary urgency was unchanged. On examination the patient was unable to stand up unaided from a wheelchair. When helped to his feet he walked about 15 feet in five minutes using a four-prong cane. There was no weakness of the lower limbs. Using a rolling walker, he advanced at a fair speed, a capability with which he was satisfied for the time being.

\section{Comment}

The occurrence of bilateral subdural hygromas in a patient with NPH qualifies as one of the rarest experiments of nature. The data are reliable except for the important observations concerning the patient's temporary improvement in gait, for which we are dependent on the family's impression. The inherent difficulty in accurately assessing a mild gait disorder on routine neurological examination is well appreciated. In this regard, the family's observations over a period of weeks or months could be unusually reliable. As a group, they were convincing and appeared to have good judgement. Aware that the subdural collections were increasing in size, they were expecting the patient to become worse, at the time of the surprising improvement.

If our interpretations are correct, the patient with NPH temporarily regained his balance and mobility when bilateral, symmetrical subdural hygromas resulted in compression and decreased size of the lateral ventricles. As the subdurals were resorbed, the ventricles re-enlarged and the gait disturbance recurred.

\section{Patient 2}

An 86-year-old retired physician noted increasing imbalance for about two years. A cranial CT scan showed greatly enlarged lateral ventricles (Figure 2A). Because of his age, surgical shunting was not considered.

Five years later, the patient had become a total invalid, living a bedchair existence. When in bed he lay immobile, aspontaneous, and spoke only in response to questions. He was unable to change his position or sit up. When assisted to the standing position, his feet were placed 12" anterior to his pelvis in a totally unstable position (hydrocephalic astasia-abasia). He was incontinent of bladder. His memory, although impaired, was relatively preserved. A cranial CT scan showed greatly enlarged ventricles.

A test withdrawal of CSF was made. The initial CSF pressure was $155 \mathrm{mmcsf}$ and $40 \mathrm{ml}$ were removed. There was remarkable improvement in his condition and next day, he was able, unaided, to move to the side of the bed, get out of bed, stand and take 12 small steps. He was more animated. Because of this response ventriculo-atrial shunting was performed by Dr. Robert Ojemann. Postoperative recovery was satisfactory and in five days, the patient was able to get out of bed on his own and walk to a chair. He fed himself for the first time in many

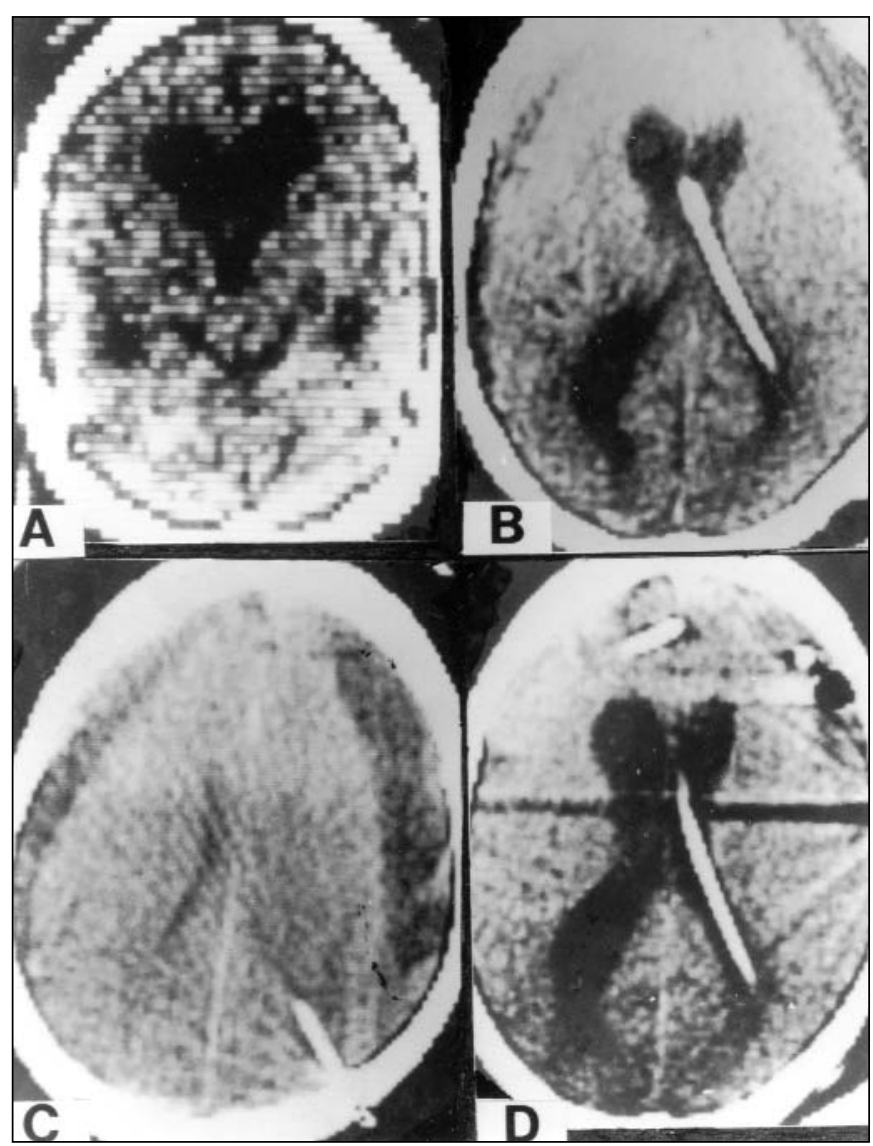

Figure 2: Patient 2. Cranial CT scans. A: Preshunt to show hydrocephalus; B: Two weeks postshunt to show large subdurals and smaller ventricles; $C$ : Six weeks postshunt showing massive subdurals and greatly narrowed ventricles; D: Three months post-shunt showing refractory hydrocephalus, intraventricular pressure is zero. 
months. He continued to improve and when discharged 14 days after surgery, he was better than he had been in two years. A CT scan at this time showed bilateral subdural collections, the left one much larger. The lateral ventricles were reduced to about half their preoperative span (Figure 2B).

Four weeks after shunting, the patient's son telephoned to report that his father had a miraculous recovery. He was active and walked with good balance. His intellect was normal and he had hosted a dinner party where he was his old, lively, conversational self. He had returned to the person of 15 or even 25 years before. Six weeks after surgery, his son telephoned again, this time to report that the patient was regressing to his preoperative condition with loss of mobility and dullness of intellect. A CT scan now showed much larger bilateral subdural collections, greater on the left. The ventricular span was about $8 \mathrm{~mm}$ (Figure 2C). On examination the patient although alert, was unable to get out of bed and when stood on his feet he again placed his feet anterior to his pelvis, and leaned backwards. When supported he walked with 6" steps.

The shunt tubing was ligated and both subdural spaces were surgically drained. In six weeks the subdural collections were smaller and the ventricular system had enlarged to its preoperative state (Figure 2D). The patient remained immobile and confused. Re-establishment of the ventriculo-atrial shunt was ineffective although apparently functioning properly. The intraventricular pressure was zero. Several further surgical attempts to improve the situation were unsuccessful. The patient entered the refractory state of post-shunt hydrocephalus associated with low CSF pressure.

\section{Comment}

It is postulated that the patient's remarkable improvement reached its optimum when the size of the subdural collections was intermediate between the two shown in Figure 2B and 2C. Patient 2 differs from patient 1 in that the ventricular system had been shunted and the striking clinical improvement could be attributed to the resultant decrease in intraventricular pressure rather than to the smaller ventricles resulting from the pressure exerted by the subdural collections. In our experience uncomplicated successful shunting in NPH never results in the marked decrease in ventricular size seen in patient 2. Evidence that lowering the CSF pressure was not, by itself, the crucial factor is provided by the later persistence of disabling deficits when the intraventricular pressure was zero. Evidence that the ventricles were being compressed can be inferred from the presence of the smaller ventricle on the side of the larger subdural collection.

\section{DiscuSsion}

The thesis being advanced here is that the subdural collections reversed the symptoms of NPH by decreasing the ventricular size. Patient 1 is more convincing in that the subdural collections were the only variable whereas in patient 2 the CSF pressure was lowered at the same time by shunting. The CSF pressure was not measured after the subdurals appeared. Patient 2 was studied by the author before patient 1 and the inference drawn at the time appeared to be confirmed by patient 1 .

At first the matter was of more than academic interest insofar as it suggested that in cases of refractory ventriculomegaly as occurred late in patient 2, surgical reduction of the intracranial space might be beneficial by secondarily causing a decrease in ventricular size. The original suggestion was that plastic extradural implants or inserts might be considered for this purpose. More recently this puzzling condition has yielded to ventricular suction. ${ }^{2}$ The idea of plastic implants, therefore, hardly is relevant at present.

Demonstration of the concept advanced here has another aspect, namely its contribution to CSF hydrodynamics and the mechanisms of symptoms. The reversal of symptoms through the reduction of ventricular size by means of subdural collections is consistent with the operation of Pascal's hydraulic principle for fluids in which $\mathrm{P} \times \mathrm{A}=\mathrm{F}$. As A increases in ventriculomegaly, $\mathrm{F}$ the total force on the ventricular wall also increases, causing symptoms, while $\mathrm{P}$ the CSF pressure remains unchanged. In the reverse situation, decreasing the ventriculomegaly, decreases A, reduces $\mathrm{F}$ and the symptoms are relieved. It has been difficult to find an avenue of approach to the principle under discussion here. The present report is the first step in that direction.

This interpretation is somewhat over-simplified for the ventricular wall, rather than being a uniform distensible membrane subject to the laws of physics, consists of complex, living tissues - the ependyma, myelinated nerve fibers, glial cells and their processes, arterioles, capillaries and venules containing circulating blood, the extracellular fluid, etc. The most that can be said is that the coming and going of the clinical manifestations strikingly mimicks the operation of Pacscal's principle. The process could well serve as a biological model. An additional aspect of our deductions depends on an assumption concerning ventricular volume. The horizontal span of the lateral ventricles was clearly decreased when the subdurals were present. From this it was assumed that ventricular volume and surface area were less also. Ventricular volume can be accurately determined using MRI.

\section{REFERENCES}

1. Adams RD, Fisher CM, Hakim S, Ojemann RG, Sweet WH. Symptomatic occult hydrocephalus with "normal" cerebrospinal fluid pressure. N Engl J Med 1965;273:117-126.

2. Bergsneider M, Peacock WJ, Mazziotta JC, Becker DP. Beneficial effect of siphoning in treatment of adult hydrocephalus. Arch Neurol 1999;56:1224-1229. 